(France is divided into "departments"). The various texts that have successively established the rules concerning the organization of the Red Plan on a local level and national level have been analyzed, and the differences they reveal have been stressed in the light of the events that have lead to its evolution.

The first emergency plan for numerous victims elaborated in the Paris area dates back to 1975 . The first Director of Medical Assistance had been named one year earlier. At the time, the regulations were those of the Paris fire brigade, and anticipated three situations: Blue Plan, 10 victims; White Plan, 20 victims; and Red Plan, 50 victims. Later, these three were grouped into a single category: the Red Plan, with three "functional chains" for collecting, selecting/treating and evacuating.

The first actual application of this system occurred in 1978 after a gas explosion in rue Raynouard, and it was obvious that there were many flaws in the functioning of the Plan. These flaws were further exposed after responding to two additional explosions involving the emergency teams, and to spontaneous evacuations done by passersby and policemen. One year later, another gas explosion in rue Saint-Ferdinand provided the opportunity to implement the Red Plan. Since then, the lessons learnt during the major interventions and from the regular training have prompted regular updates in the regulations. The 1986 terrorist attacks in Paris made it clear that it was necessary to integrate the SAMU (urgent medical aid service) into the Red Plan, a decision that proved satisfactory later with the 1987 and 1988 train accidents, primarily that of Gare de Lyon. The new series of terrorist attacks in 1995 was the occasion to improve the way victims are cared for, thanks to the creation of a center for those implicated in the accident, and a specification in the role of the emergency medical-psychological department. In 1999, a new step was made due to the special geographical context of the Paris region, when an "interdepartmental" (interregion) Red Plan was adopted along with a new medical file.

Conclusion: Emergency aid was born from the war experience. The application of the regulations to actual and major accidents with limited effects has generated the conception of a more effective emergency plan, whose regulations should remain flexible in order to encourage regular evolutions.

Key words: casualty collection; chains, emergency aid; evacuation; functional; multiple casualties; plan; planning; preparedness; regulations; SAMU

Prehosp Disast Med 2001;16(2):s64.

\section{Sydney 2000: Olympic Stadium Medical Programme Dr.John Sammut} Ashbury, AUSTRALIA

The Sydney 2000 Olympic Stadium is the world's largest ever purpose built Olympic facility, with a capacity of 118,000 people. Over the course of the Olympic programme, ( 8 days of athletics competition as well as the Opening and Closing Ceremonies), more than 1.9 million people passed through the turnstiles of the Olympic Stadium. Meeting the challenge to provide timely, effec- tive, and efficient emergency care to all people in the stadium is discussed. It begins by looking at the challenges that needed to be overcome; it details the operating plan that ultimately was put in place; it outlines the disaster preparedness programme, the resources committed to implementing the programme, and the results achieved.

Ultimately, the plan involved over 100 medical staff providing medical care for over 100,000 people for each session of competition. How this was carried out is detailed and the activity of the programme is presented: $100-120$ people treated per session: $50-60$ of these needed basic first aid, and 50-60 needed more formal medical intervention (detailed medical assessment and invasive interventions). Ultimately, 5-7 people per session were transferred by ambulance to a hospital. No one died.

Key words: first aid; interventions; mass gatherings; medical care; Olympics; plan; preparedness; stadium; staffing

E-mail: john.sammut@unsw.edu.au

Prehosp Disast Med 2001;16(2):s64.

\section{Fifty-month CEP-Experience in an Area of a Half- million People}

Mr. Bernd Michael Schneider, FICS;A. Beck;

J. Erdmann; R. Fromme; H. Gerstacker; R. Prestele; W.D. Seidl; W. Koehle; L. Kinzl; A. Wipp

Hirtenberg, GERMANY

Introduction: Following the education as Coordinating Emergency Physicians (CEPs) according the Bavarian Rescue Laws (BRLs), we formed a voluntarily acting CEP group in our rescue region in Western Bavaria in January 1996. The group was accredited by the authorities in May 2000 . To improve the performance of our missions, we analyzed the system capacities according $J$. de Boer ${ }^{1}$ and tried to implement M. Villareal's QC tools. ${ }^{2}$

Methods: From January 1996 to February 2001, we handled 50 missions that were prospectively registered and analyzed since June 1997. According to de Boer's Criteria for Disaster Preparedness, we calculated the capacities of our rescue chain using the elements: (1) medical rescue capacity, (2) medical transport capacity, and (3) the local hospital treatment capacity according to the number of available hospital beds. We did these calculations to be prepared for the EMS management of the World Exhibition of Fire Brigades, which took place in our city in June 2000. M. Villareal's tools for QC were tested on scene and in postevent meetings to gain best information and feedback for our learning curve as CEPs.

Results: In total, we served 23 missions during daytime (4 in the morning, 19 in the afternoon), and 27 missions were necessary during the night. Regarding the reasons for the calls, there were 24 fire alarms, 14 accidents (cars, railroad, aircraft), 4 poisonings, 5 explosions or bomb alarms, and 3 during mass gatherings. Of these missions, 41 were graded as events of first degree ( according to Villareal's staging system) and 9 required additional manpower like SEGs (special acting groups) so that these events were graded as 2 nd degree casualities according to Villareal.

From the total number of 3,724 hospital beds, a theo- 
retical hospital treatment capacity of 112 patients/hour was calculated for a performance score of level 5 . This is served by a transport capacity of 49 ambulances directed by 8 emergency physician cars. For increasing the rescue capacities, the rescue teams could be supported by 7 local SEGs (pecial acting groups) and 5 helicopters from the vicinity.

In total, up to $05 / 2000$ voluntary CEP system took responsibility for about 550 victims of minor injuries. According de Boer's criteria for disaster scoring, we had to deal with events of a disaster severity score from 1 to 6 . The severity index was calculated between 0.3 and 3 .

Conclusions: To be able to distinguish between the three degrees of Villareal's differentiation of MCs: $\mathrm{I}=\mathrm{B} 0, \mathrm{II}=\mathrm{B} 0$, III $=\mathrm{B} 0$, it is necessary to know exactly the capacities of your local rescue chain elements. It is essential to be able to distinguish between $\mathrm{MCs} \mathrm{II}=\mathrm{B} 0$ and $\mathrm{III}=\mathrm{B} 0$ because you have to call for help in the vicinity in time in case of MC $\mathrm{III}=\mathrm{B} 0$. So you should be able to prevent that your local MC might end as a disaster because of bottleneck problems within your local system capacities.

\section{References}

1. de Boer J: Criteria for the assessment of disaster preparedness - II. Prebosp Disast Med 1997;12:13-16.

2. Villareal M: Quality control module for mass casualities. Prehosp Disast Med 1997;12:200-209.

3. de Boer J: Definition, classification and scoring of disaster. In: Handbook of Disaster Medicine. De Boer J,. Dubouloz M (ed), VDW publisher 1999, pp $227-228$.

Key words: capacities; classification; coordinating emergency physicians; disaster; performance; quality assurance E-mail: bm.schneider@medizin.uni-ulm.de

Prehosp Disast Med 2001;16(2)s65.

\section{The Complications in Excimer Laser In-Situ \\ Keratomileusis for Severe Myopia}

Shi Xiuru; He Tiangeng; Wang Lijun; Wu Shi Ying

Tianjing Medical University, Tianjing, PEOPLE'S REPUBLIC CHINA

Objective: To evaluate the safety and efficacy of excimer laser in-situ keratomileusis for severe myopia.

Method: 463 eyes of 237 cases which ranged from $-6.00 \mathrm{D}$ to $-22.00 \mathrm{D}$ were operated upon using Lasik using SCMD Microkeratome and NIDEK EC-500 excimer laser system. The complications and prognosis were analyzed retrospectively.

Results: Postoperative, uncorrected visual acuity increased significantly, and $75.3 \%$ of the patients achieved preoperative best corrected visual acuity or better. The perioperative complications included: incomplete corneal flap $(0.86 \%)$; free cap $(0.43 \%)$; decentred flap $(0.22 \%)$; and limbus hemaorrhage $(7.3 \%)$. The postoperative complications included: particulate debris under the repositioned flap (2.8\%); over or undercorrection (9.8\%); and epithelial interface ingrowth $(0.65 \%)$.

Conclusion: Lasik for severe myopia proved to be safe and effective, although it needed to be improved microkeratome and experience.

Key words: acuity; complications; efficacy; excimer laser; keratomileusis; myopia; safety

Prehosp Disast Med 2001;16(2):s65.

\section{Reducing Community Vulnerability of Lalitpur Submetropolitan City Dr. Bijaya K. Shrestha}

The high rate of urbanization and haphazard urban growth coupled with change in the economic base has transformed the tiny town of Lalitpur into a submetropolitan city. Founded in $299 \mathrm{AD}$ along Tibetan and Indian trade routes, the town developed based on Hindu and Buddhists planning principles into the present form. Lalitpur, within its 22 municipal wards over an area of 459 hectares, is comprised of both planned and unplanned, as well as old and new urban fabrics, exhibiting the socioeconomic reality and development process that prevailed in those earlier periods.

The consequences of this transformation not only are limiting physically, such as destruction of traditional homogeneous building stocks into inferior parts, severe deficiencies in basic urban services, conversion of courtyards and pedestrian lanes into "death traps" and so on, but also on reduction of an individual's or society's ability to cope with hazards, thus making the old neighborhood more vulnerable. The government's response to deal with various problems associated with this process through enforcing building legislation and rescue operation on an ad hoc basis is insufficient and discouraging.

This paper examines the community vulnerability from an integrated approach of Lalitpur, just next to the capital city of Kathmandu. It has four objectives. First, it demonstrates the natural hazards in the city, considers seismic risk and socioeconomic structure including variables in infrastructure, building materials, and population vulnerabilities. Second, it analyzes the preparedness level and response capacity of the city (and society) for vulnerability analysis. Also, a case study of a typical neighbourhood in the historical core area is examined in order to demonstrate the process of urban transformation and its consequences on neighbourhood vulnerability. Third, it identifies various reasons of vulnerability increases, and then, assesses the risk analysis (future probable damage). Finally, it proposes some recommendations for public authorities, communities, and policy makers in the fields of planning and development, vulnerability analysis, and capacity of local government (and ward office) and local resource mobilisation and community awareness.

Key words: community vulnerability; Lalitpur; seismic risk; socioeconomy; urban transformation

E-mail: shrestha@hyogo.uncrd.or.jp

Prebosp Disast Med 2001;16(2):s65.

\section{Management of Calcium Oxide Intoxication M. Simon, ${ }^{1}$ M. Dubois, ${ }^{2}$ F. Van Trimpont ${ }^{3}$ \\ 1. Rinsis, Mons, BELGIUM \\ 2. Chr Warquignies, BELGIUM \\ 3. Chu Ambroise Pare, Mons, BELGIUM}

Introduction: On an industrial site, an intoxication of a large number of workers by calcium oxide has necessitated strict triage so as to avoid a massive evacuation toward the hospitals. 